\begin{tabular}{|c|c|}
\hline \multirow{3}{*}{ 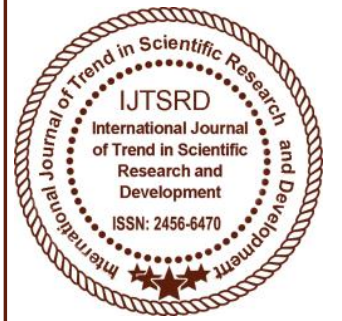 } & $\begin{array}{l}\text { International Journal of Trend in Scientific } \\
\text { Research and Development (IJTSRD) }\end{array}$ \\
\hline & International Open Access Journal \\
\hline & ISSN No: 2456 - 6470 | www.ijtsrd.com | Volume - 1 | Issue - 5 \\
\hline
\end{tabular}

\title{
Visualizing Chrome Browser History using Exploratory
}

\author{
Dharani Kumar.C \\ SRM University, Katankulathur, \\ Chennai, Tamil Nadu, India
}

\author{
G Vadivu \\ SRM University, Katankulathur, \\ Chennai, Tamil Nadu, India
}

\begin{abstract}
Web browsers are at the core of online user experience, enabling a wide range of web applications like audios, videos, games, software, etc. It is very interesting from an individual point of view to discover patterns from web browsing history.Web browsers collect a history of the user's activity, and this history data can be processed by browser add-ons using the browser's extension API.Add-ons may slow down your web browser. Add-ons may transfer into malwares. Extensions are vulnerable in nature. It may sometimes install third party applications. we are using chrome sign in feature instead of using extensions. It is fast and protects you with username and password. Exploratory software is used to visualize, which is free for students. Result: The browsing data is collected using a Gmail account and the data is visualized using exploratory software. Hence the data can be protected and used by the owner of the Gmail account. It is also possible to find the relation between the websites and to create a network between them using ucinet.
\end{abstract}

KEYWORDS: Exploratory, Browsing History, Extensions, Ucinet.

\section{INTRODUCTION:}

In computing, the web browsing history refers to the list of web pages a user has visited recently and associated data such as page title and time of visit which is recorded by web browser software as standard for a certain period of time. Web browser software does this in order to provide the user with a back button and a history list to go back to pages they have visited previously as well as displaying visited links rather than relying on the user to remember where they have been on the web. In addition to the web browser software itself, third-party services can also record a user's web browsing history (completely or partially). For example, in google web history, the clicks of registered users are recorded and stored in individual user histories, each of which are browsable and searchable by that user (this is in addition to the click-tracking Google records for its own internal purposes, such as advertising click tracking). If the user installs the google toolbar, all pages that the user visits while logged into Google on that computer may be recorded as well. A potential benefit to the user is that they can review and search through all of their web browsing history on any computer, but this can have privacy implications. Web browsing history is not published anywhere publicly by default, whether a user uses their own browser's history functionality or a third-party service, because this would have huge negative privacy implications and would reflect negatively on the reputation of a software or service provider who did such a thing. If a user has not disabled ("paused") Google's collection of Web History, and has a Google Account which they use, choosing a strong password for that account is 
important to prevent hackers gaining access to confidential data.

\section{LITERATURE REVIEW:}

\subsection{EXISTING SYSTEM:}

Google chrome extension is used to collect the data of browsing history. Once the extension is installed an icon appears right next $t$ the address bar. If the user clicks the icon, it will extract the web history of the user and forms the weighted network. The user can see clusters of websites and could navigate to a website by clicking on the region allotted to it in tree map. The network of the web history is rebuilt with the latest data every time the user refreshes the page. Note that the clusters of most frequently visited websites tend to be placed towards the center of the bounding box making it easier for the user to navigate to those pages.

\subsection{PROPOSED SYSTEM:}

Signing in to Chrome brings your bookmarks, history, and other settings to all your devices. Anything you update on one device instantly updates everywhere else, and your Chrome stuff is safe in case anything happens to your computer. It's your web. Take it with you. So it is easy and safe to save data. We can also able to collect data from google using takeout google feature. Collect the data and save it in system. Upload the collected data in the exploratory software to visualize the browsing history. It is possible to create a network from the browsing history data using ucinet software.

\subsubsection{METHODOLOGY:}

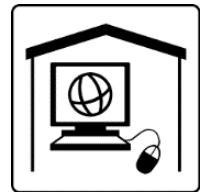

Sign in to chrome history

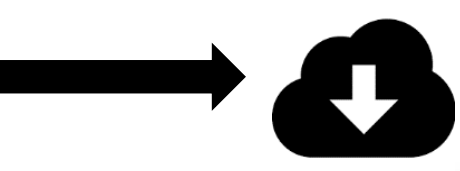

Download browser

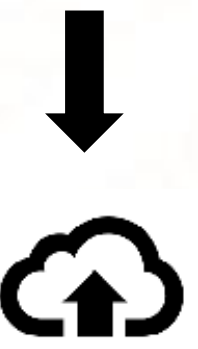

Upload it in exploratory

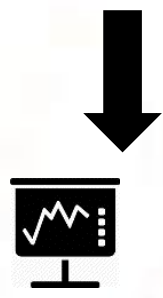

Visualizing the data

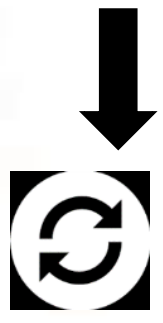

Generate csv file

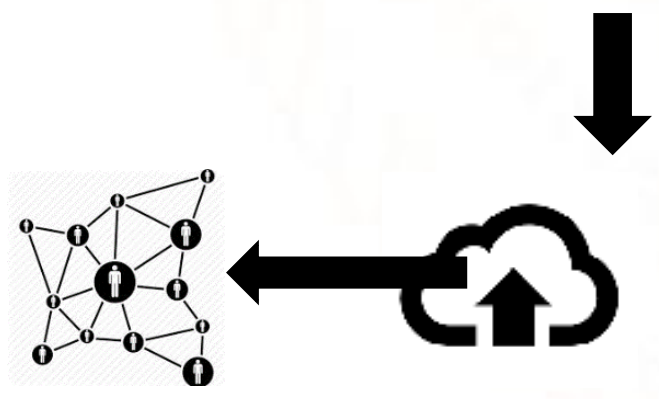

Fig 1: Flow Diagram of the Method Used 
International Journal of Trend in Scientific Research and Development (IJTSRD) ISSN: 2456-6470

Creating a network Upload it in ucinet

\subsubsection{NETWORK DIAGRAM:}

\section{FIG 1.2: NETWORK DIAGRAM USING UCINET}

\section{Q 0 G}

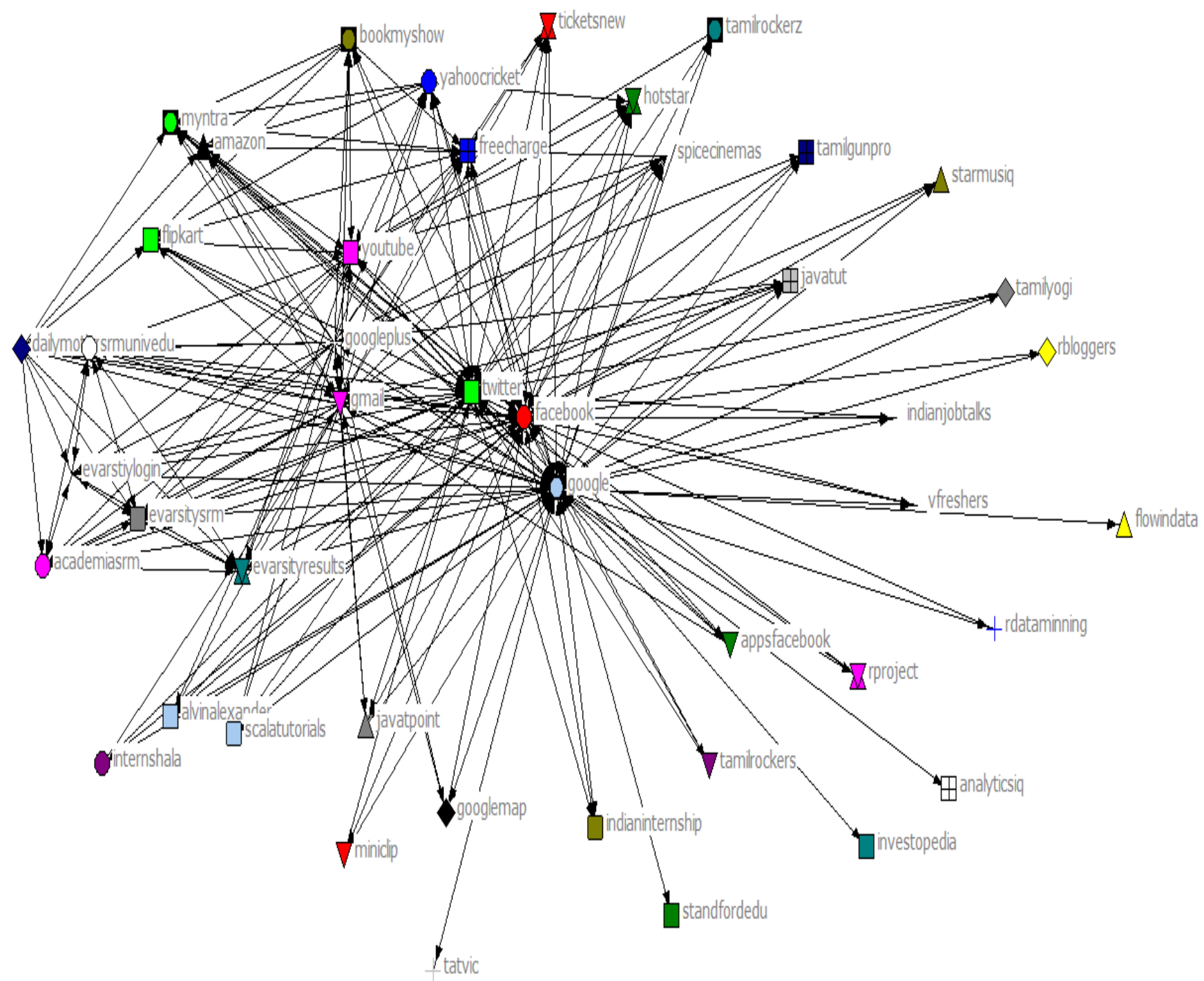

\subsubsection{EGO NETWORK:}

Ego networks consist of a focal node ("ego") and the nodes to whom ego is directly connected to (these are called "alters") plus the ties, if any, among the alters. Of course, each alter in an ego network has his/her ownego network, and all ego networks interlock to form the human social network. 


\section{FIG 2: EGO BASED ON SINGLE USERID:}

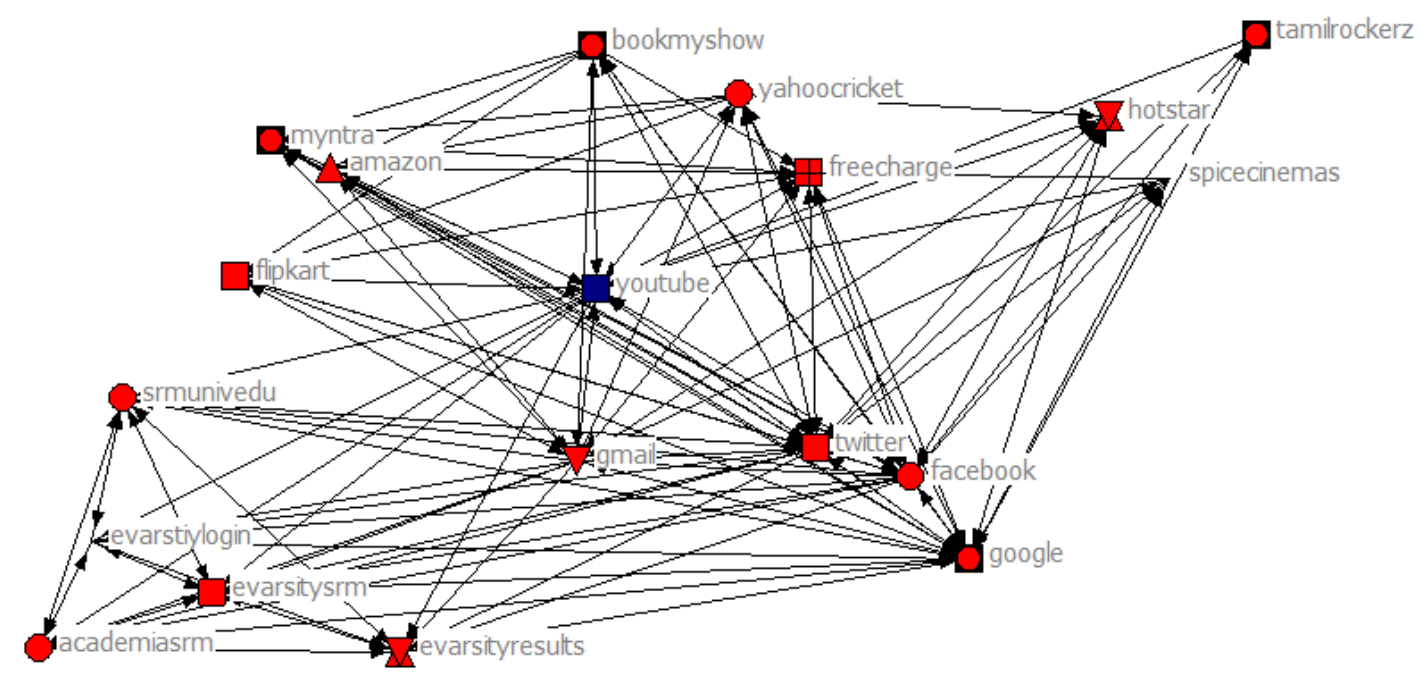

\section{FIG2.1: EGO BASED ON MULTIPLE USERID:}

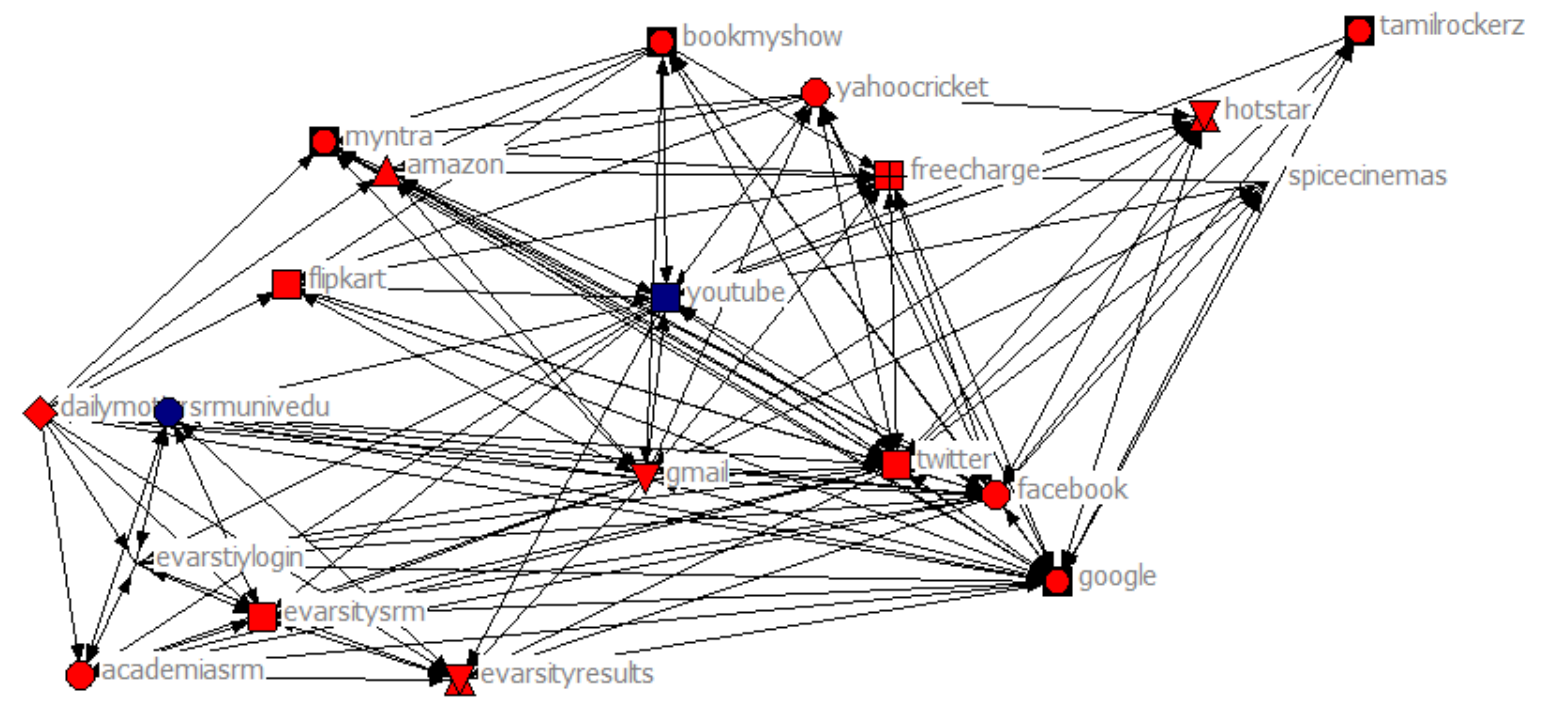

\section{BETWEENESS CENTRALITY:}

In graph theory, Betweeness centrality is a measure of centrality in a graph based on shortest paths. Betweeness can be calculated using ucinet software. 
International Journal of Trend in Scientific Research and Development (IJTSRD) ISSN: 2456-6470

\section{CALCULATING BETWEENESS USING UCINET:}

Un-normalized centralization: 53278.756

\begin{tabular}{|c|c|c|c|}
\hline & & $\begin{array}{c}1 \\
\text { Betweeness }\end{array}$ & $\begin{array}{c}2 \\
\text { nBetweeness } \\
\end{array}$ \\
\hline 1 & google & 1196.125 & 60.410 \\
\hline 13 & facebook & 293.902 & 14.844 \\
\hline 15 & twitter & 153.448 & 7.750 \\
\hline 3 & gmail & 64.820 & 3.274 \\
\hline 16 & youtube & 17.448 & 0.881 \\
\hline 4 & googleplus & 5.917 & 0.299 \\
\hline 27 & freecharge & 4.248 & 0.215 \\
\hline 35 & amazon & 1.442 & 0.073 \\
\hline 34 & Flipkart & 1.442 & 0.073 \\
\hline 36 & Ebay & 1.313 & 0.066 \\
\hline 37 & myntra & 1.099 & 0.056 \\
\hline 14 & yahoocricket & 0.456 & 0.023 \\
\hline 30 & ticketsnew & 0.206 & 0.010 \\
\hline 28 & bookmyshow & 0.206 & 0.010 \\
\hline 29 & spicecinemas & 0.206 & 0.010 \\
\hline 19 & tamilgunpro & 0.144 & 0.007 \\
\hline 39 & javatpoint & 0.129 & 0.007 \\
\hline 17 & dailymotion & 0.129 & 0.007 \\
\hline 2 & googlemap & 0.129 & 0.007 \\
\hline 38 & alvinalexander & 0.129 & 0.007 \\
\hline 33 & hotstar & 0.063 & 0.003 \\
\hline 9 & standfordedu & 0.000 & 0.000 \\
\hline 8 & rdataminning & 0.000 & 0.000 \\
\hline 24 & internshala & 0.000 & 0.000 \\
\hline 20 & tamilrockers & 0.000 & 0.000 \\
\hline 21 & tamilrockerz & 0.000 & 0.000 \\
\hline 22 & starmusiq & 0.000 & 0.000 \\
\hline 18 & tamilyogi & 0.000 & 0.000 \\
\hline 6 & flowindata & 0.000 & 0.000 \\
\hline 7 & rbloggers & 0.000 & 0.000 \\
\hline 31 & miniclip & 0.000 & 0.000 \\
\hline 32 & appfacebook & 0.000 & 0.000 \\
\hline 23 & indianinternship & 0.000 & 0.000 \\
\hline 11 & investopedia & 0.000 & 0.000 \\
\hline 12 & analyticsiq & 0.000 & 0.000 \\
\hline 25 & vfreshers & 0.000 & 0.000 \\
\hline 26 & indianjobtalks & 0.000 & 0.000 \\
\hline 10 & rproject & 0.000 & 0.000 \\
\hline 5 & tatvic & 0.000 & 0.000 \\
\hline 40 & javatut & 0.000 & 0.000 \\
\hline 41 & scalatutorials & 0.000 & 0.000 \\
\hline 42 & srmunivedu & 0.000 & 0.000 \\
\hline 43 & evarsityresults & 0.000 & 0.000 \\
\hline 44 & evarsitysrm & 0.000 & 0.000 \\
\hline 45 & evarstiylogin & 0.000 & 0.000 \\
\hline
\end{tabular}

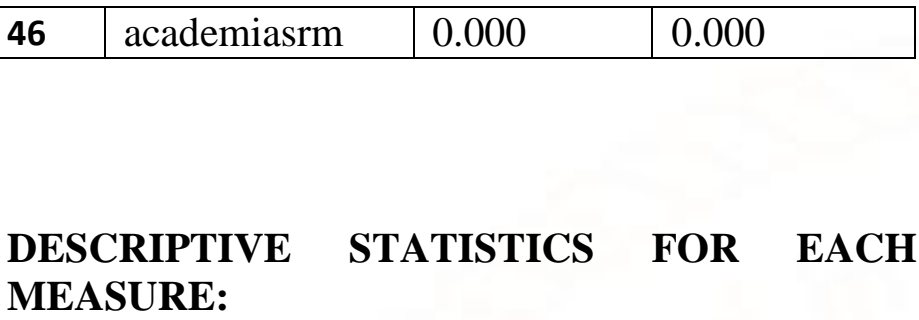

\begin{tabular}{|llll|}
\hline \multicolumn{2}{|c|}{$\begin{array}{l}\text { 2 } \\
\text { Betweeness } \\
\text { nBetweeness }\end{array}$} \\
\hline 1. & Mean & 37.891 & \\
\hline 2. & Std Dev & 179.320 & 1.914 \\
\hline 3. & Sum & 1743.000 & 9.057 \\
\hline 4. & Variance & 32155.703 & 88.030 \\
\hline 5. & SSQ & 1545206.875 & 39.021 \\
\hline 6. & MCSSQ & 1479162.375 & 3772.989 \\
\hline 7. & Euc Norm & 1243.063 & 62.781 \\
\hline 8. & Minimum & 0.000 & 0.000 \\
\hline 9. & Maximum & 1196.125 & 60.410 \\
\hline 10. & N of Obs & 46.000 & 46.000 \\
\hline
\end{tabular}

Network Centralization Index $=59.80 \%$ 


\section{FIG 3: OUTPUT FOR CENTRALITY MEASURE:}

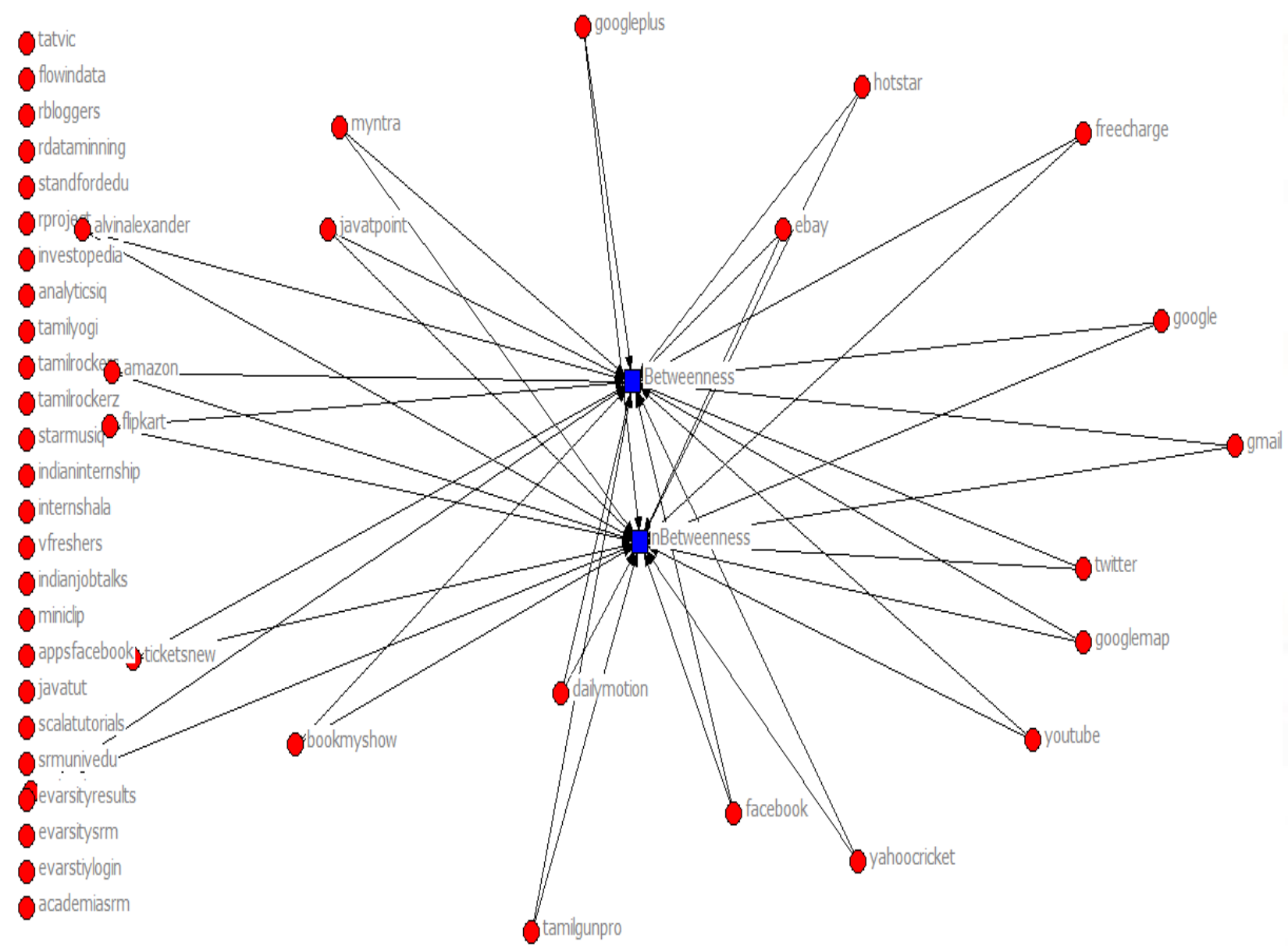

\section{OUTPUT:}

\section{FIG 4.1: SUMMARY OF THE DATA}

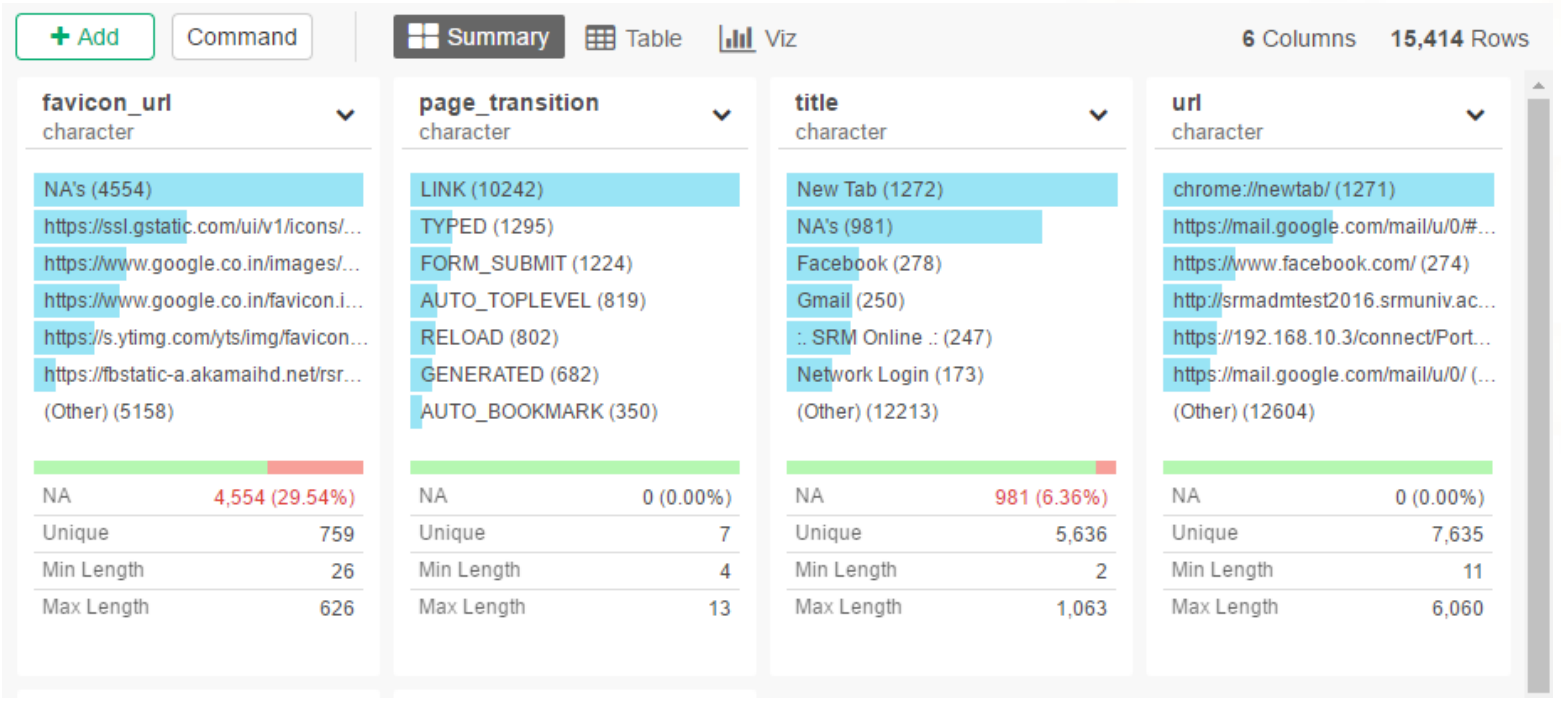


International Journal of Trend in Scientific Research and Development (IJTSRD) ISSN: 2456-6470

\section{FIG 4.2: SUMMARY OF THE DATA}

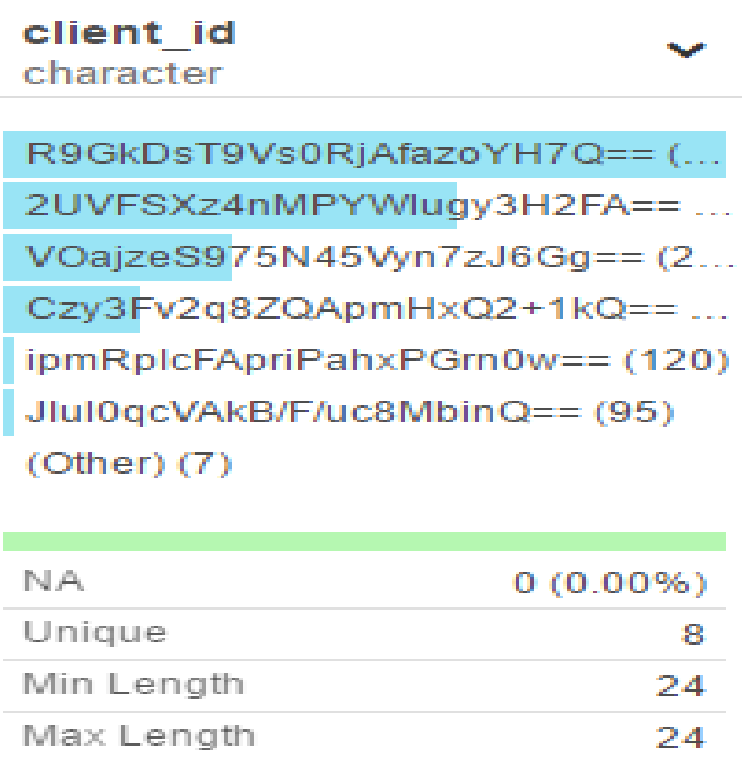
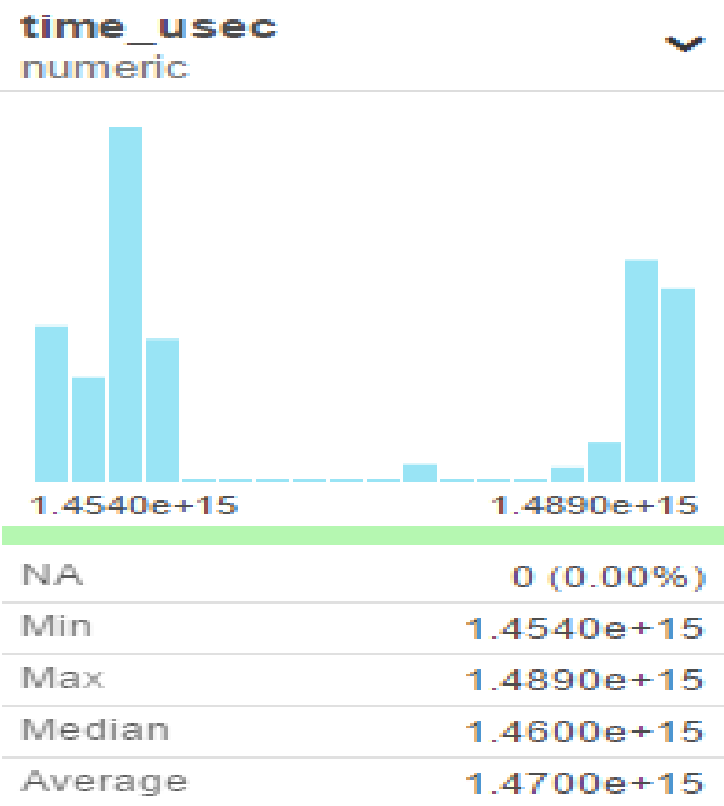

Number of times visited

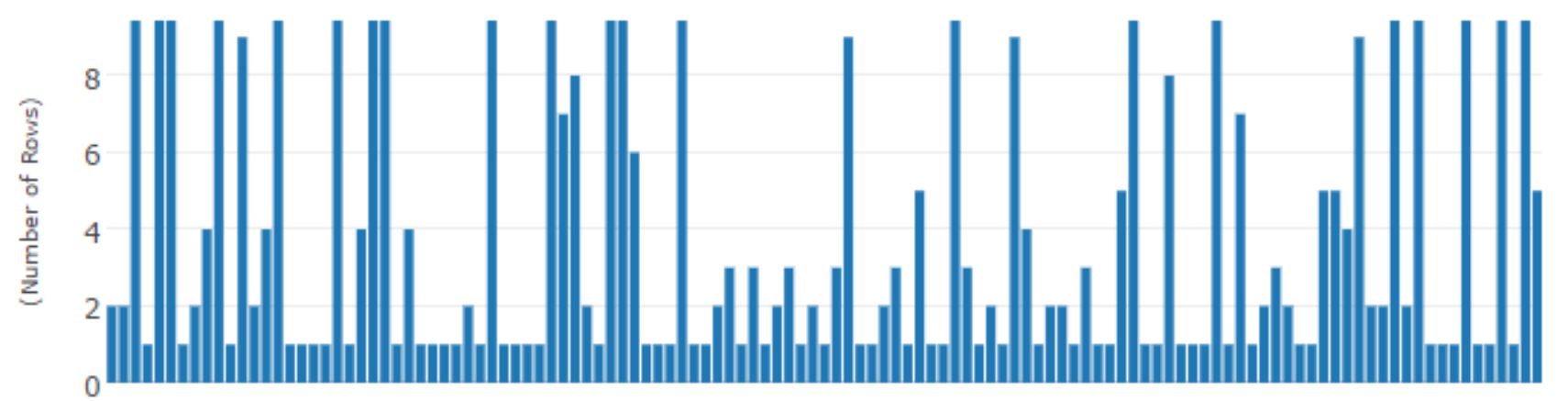

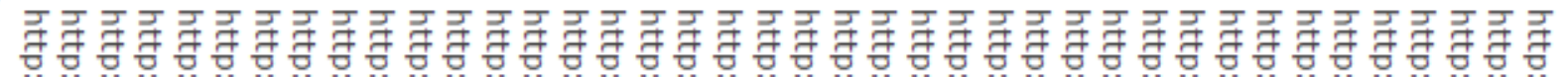

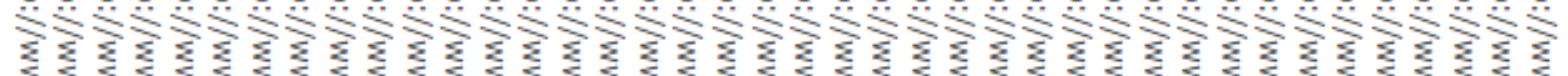

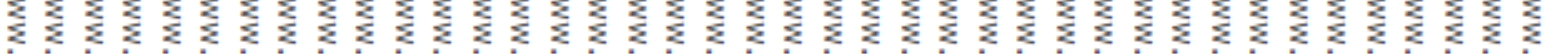

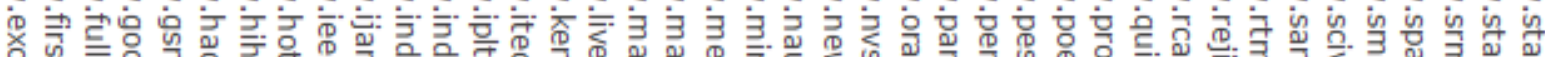

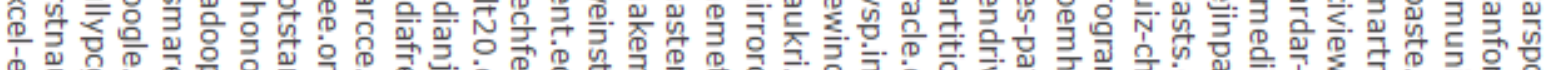

市

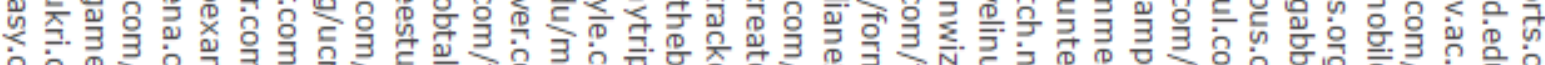

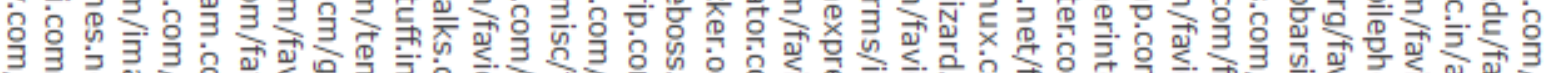

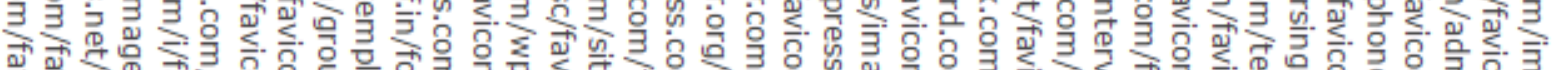

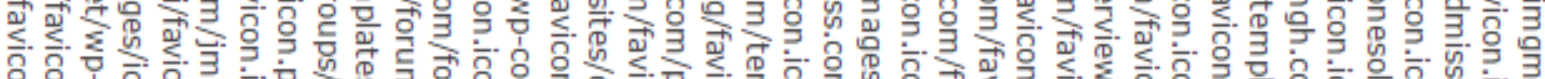

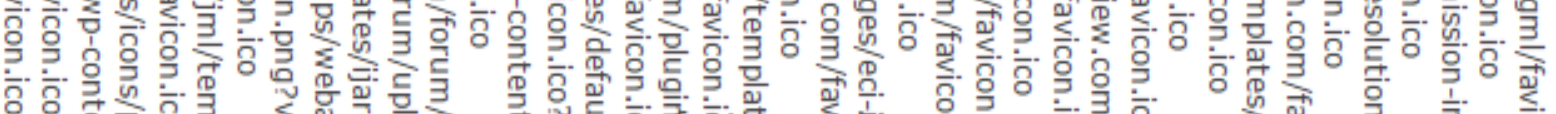

FIG 4.3: NUMBER OF TIMES VISITED 


\subsection{WEBSITES (EXAMPLES):}

1. https://takeout.google.com/settings/takeout

2. https://myaccount.google.com/privacy?pli=1

3. https://github.com/jimhester/gmailr

4. http://www.rdatamining.com/data

5. https://www.r-bloggers.com/an-example-ofsocial-network-analysis-with-r-using-packageigraph/

6. http://web.stanford.edu/ messing/RforSNA.html

7. http://www.srmuniv.ac.in/

8. http://www.srmuniv.ac.in/announcement/enggtech-results

9. http://evarsity.srmuniv.ac.in/srmwebonline/exam/ onlineResult.jsp

10. https://www.tutorialspoint.com/java/java_object_c lasses.htm

\section{CONCLUSION:}

Hence visualizing the browsing history data using exploratory is achieved and Network diagram is used to find the relationship between the websites. Ego network based on single id and multiple id also achieved. Ucinet is used to find the Betweeness in the network.

\section{ACKNOWLEDGMENTS:}

This research has been supported by ucinet, exploratory, chrome, Gmail.

\section{FUTURE ENHANCEMENT:}

In future we may try to use another web browser to get the browsing history data and visualizing it and finding the ego between the websites.

\section{REFERENCES:}

1. Graphical Histories for Visualization: Supporting Analysis, Communication, and Evaluation by Jeffrey Heer, Jock D. Mackinlay, Chris Stolte, and ManeeshAgrawala.

2. Using Graphic History in Browsing the World Wide Web. Proc. World Wide Web by Ayers E.Z., Stasko J.T.

3. A Model and Framework for Visualization Exploration. IEEE Trans. on Visualization and Computer Graphics by Jankun-Kelly T.J., Ma K.L., Gertz.

4. In INFOVIS 05: Proceedings of the Proceedings of the 2005 IEEE Symposium on Information Visualization, page 7, Washington, DC, USA,
2005. IEEE Computer Society by Michael Balzer and Oliver Deussen.

5. Integrating Back, History and Bookmarks in Web Browsers by Kaasten S., Greenberg S.

6. An exploratory study of ego networks in an email network by Angel X. Chang, Computer Science Department Stanford University Stanford.

7. A set of measures of centrality based on betweenness" by L. C. Freeman

8. M. Everett and S. P. Borgatti. Ego network Betweeness. Socila Networks.

9. R Vidhya, G Vadivu, Research Document Search using Elastic Search, Indian Journal of Science and Technology 9 (37), 2016.

10. T. Y. J. Naga Malleswari , G. Vadivu, "Map reduce: A Technical Review", Indian Journal of Science and Technology, Vol 9(1), January 2016.

11. Discovering Social Circles in Ego Networks by J. McAuley, J. Leskovec. ACM Transactions on Knowledge Discovery from Data (TKDD), 2014.

12. The Network Completion Problem: Inferring Missing Nodes and Edges in Networks by $\mathrm{M}$. Kim, J. Leskovec. SIAM International Conference on Data Mining (SDM) 2011.

13. K.Sornalakshmi, G.Vadivu, "A Survey on Realtime Analytics Framework for Smart Grid Energy Management", International Journal of Innovative Research in Science, Engineering and Technology, March 2015.

14. M. Handcock, A. Raftery, and J. Tantrum. 2007a. Model-based clustering for social networks. Journal of the Royal Statistical Society Series A.

15. P. Krivitsky, M. Handcock, A. Raftery, and P. Hoff. 2009. Representing degree distributions, clustering, and homophily in social networks with latent cluster random effects models. Social Networks.

16. Hanneman, Robert A. and Mark Riddle. 2005. Introduction to social network methods. Riverside, CA: University of California, Riverside (published in digital form.

17. Navin, G. Vadivu, "Big Data Analytics for Gold Price Forecasting Based on Decision Tree Algorithm and Support Vector Regression (SVR)", International Journal of Science and Research (IJSR), March 2015.

18. P. Borzymek, M. Sydow, and A. Wierzbicki, "Enriching trust prediction model in network with user rating similarity, " in Computational Aspects of Social Networks. IEEE, 2009, pp. 40-47. 
19. Fusion based approach to discovering social circles in EGO networks A. Kamal; M. M. LutfeElahi ; Bruce Poon; M. Ashraful Amin.

20. G.Vadivu, Waheeta Hopper, “Ontology Mapping of Indian Medicinal Plants with Standardized Medical Terms", Journal of Computer Science, ISSN 1549-3636., Aug, 2012. 